Arq. Bras. Med. Vet. Zootec., v.58, n.5, p.918-924, 2006

\title{
Efeito do período de jejum pré-abate sobre o rendimento de carcaça de frango de corte
}

\author{
[Effect of pre-laughter fasting periods on the carcass yielding of commercial broilers]
}

\author{
D.N. Schettino, S.V. Cançado, N.C. Baião, L.J.C. Lara, T.C. Figueiredo, W.L.M. Santos \\ Escola de Veterinária - UFMG \\ Caixa Postal 567 \\ 30120-970 - Belo Horizonte - MG.
}

\begin{abstract}
RESUMO
Avaliaram-se os efeitos de cinco períodos (quatro, oito, 12, 14 e 16 horas) de jejum pré-abate sobre a perda de peso e rendimento de carcaça e cortes de frangos de corte. Foram utilizados 240 frangos (120 machos e 120 fêmeas), linhagem Cobb, criados até 44 dias de idade. No $44^{\circ}$ dia, as aves foram separadas de acordo com o período de jejum (tratamentos) e o sexo, cada tratamento com 24 repetições. Nos tratamentos de quatro, oito, 12 e 16 horas, o jejum foi alimentar e no tratamento de 14 horas, o jejum foi alimentar e hídrico. O teste utilizado para as análises das médias foi o SNK (Student-Newman-Keuls). Foram analisadas as seguintes variáveis: perda de peso vivo após o jejum, taxa de absorção de água pela carcaça, rendimentos da carcaça inteira e dos cortes comerciais coxa e sobrecoxa, peito, dorso, asa, pés e cabeça e pescoço, rendimentos da moela e fígado e peso dos intestinos. Os períodos de jejum de oito, 12, 14, e 16 horas apresentaram maior rendimento de carcaça, sendo superiores ao período de quatro horas de jejum $(\mathrm{P} \leq 0,05)$. $\mathrm{O}$ tratamento de quatro horas de jejum apresentou maior rendimento de fígado e peso de intestino em relação aos demais tratamentos $(\mathrm{P} \leq 0,05)$. O período de jejum não influenciou a taxa de absorção de água nem o peso de moela $(\mathrm{P}>0,05)$. As fêmeas absorveram mais água do que os machos, e apresentaram rendimentos de carcaça e cortes comerciais superiores aos dos machos $(\mathrm{P} \leq 0,05)$.
\end{abstract}

Palavras-chave: jejum pré-abate, rendimentos de carcaça, frangos de corte

\begin{abstract}
This experiment was designed in order to evaluate the effect of five intervals of pre-slaughter fasting (four, eight, 12, 14 and 16 hours) on weight loss, carcass yielding and poultry cuts yielding of broiler chickens. A total of 120 males and 120 females broiler chickens of Cobb lineage were raised during 44 days. On the $44^{\text {th }}$ day, chickens were grouped according to their fasting period (treatments) and gender. Each treatment was composed of 24 repetitions. Animals of the of four, eight, 12 and 16 hours treatments were not fed ration while animals of the 14 hours fasting treatment were not fed ration or water. The statistical test used for mean comparison was SNK (Student-Newman-Keuls). The following variables were analyzed: loss of live weight, rate of water absorbed by carcass; whole carcass and commercial cuts (legs and forelegs, chest, dorsum, wings, feet and head and neck) yielding; gizzard and liver yielding as well as intestinal weight. The fasting periods of eight 12, 14 and 16 hours showed greater carcass yielding $(P<0.05)$ being higher than those from the four hours fasting period. The four hours fasting group showed the highest yielding of liver and intestinal weight in relation to the other groups $(P \leq 0.05)$. The fasting period did not influence the rate of water absorption or the gizzard weight $(P>0.05)$. Females retained more water than males and showed higher carcass and commercial cuts yielding than males $(P<0.05)$.
\end{abstract}

Keywords: fasting, pre-slaughter, carcass yielding, broiler chicken

Recebido em 2 de maio de 2006

Aceito em 14 de setembro de 2006-11-17

* Autor para correspondência (corresponding author)

E-mail: silvana@vet.ufmg.br 


\section{INTRODUÇÃO}

O período pré-abate dos frangos, que vai desde a pesagem até o abate, possui aproximadamente 24 horas de duração e é, provavelmente, a etapa da cadeia produtiva que exerce maior influência nos índices qualitativos e quantitativos dos produtos do abatedouro. Dentre os fatores que antecedem o abate, o período de jejum de ração é o mais importante, pois pode evitar contaminações e prejuízos nos rendimentos das carcaças caso seja feito de maneira correta. A ração fornecida aos frangos é responsável por 65 a $70 \%$ do custo de produção e quando o período de jejum não é realizado, uma grande quantidade de ração não digerida é eliminada durante a evisceração. Assim, é interessante conhecer períodos de jejum que não comprometam o rendimento de carcaça, e que assegurem a economia de ração. Além disso, o jejum pré-abate pode reduzir os efeitos do estresse calórico, já que o metabolismo da ave é reduzido durante o jejum, e diminuir os riscos de contaminações de carcaças por rompimento de vísceras no abatedouro.

O Ministério da Agricultura, Pecuária e Abastecimento (MAPA) preconiza um tempo mínimo de seis horas e um máximo de oito horas de suspensão da ração para as aves que serão abatidas, pois assim possíveis contaminações durante o processamento industrial poderão ser evitadas (Portaria..., 1998).

Benibo e Farr (1985), trabalhando com períodos de jejum de ração e água antes do abate de 10, 15 e 20 horas verificaram que a perda de peso vivo aumentou com o aumento dos períodos de jejum e que os machos apresentaram maiores perdas de peso vivo do que as fêmeas. Demonstraram também que o rendimento de carcaça diminuiu à medida que o período de jejum de ração aumentou, e que não houve influência da taxa de absorção de água pelas carcaças, porém as fêmeas, em valores absolutos, absorveram mais água que os machos, mas não houve diferença estatística entre os sexos.

Rasmussen e Mast (1989) avaliaram o efeito do jejum de ração na composição e qualidade da carne de frangos de corte, e verificaram que as perdas de peso vivo e as taxas de absorção de água pela carcaça foram influenciadas pelos períodos de jejum e aumentaram gradualmente com o aumento dos tempos de jejum. Os rendimentos de carcaça não foram afetados pelos períodos de jejum.

Lyon et al. (1991) mostraram que os rendimentos de carcaça de frangos de corte submetidos a períodos de jejum de zero, oito, 16 e 24 horas apresentaram diferenças, sendo que o menor rendimento de carcaça foi observado no tempo zero hora de jejum. Também Baião et al. (1992) concluíram que o período de jejum de 12 horas promoveu boa economia de ração e não afetou o peso das carcaças.

Northcutt et al. (1997) realizaram um experimento para verificar a relação do período jejum pré-abate com as condições das vísceras e não encontraram efeitos significativos para os rendimentos de fígado em todos os períodos de jejuns (zero, três, nove, 12, 14, 16 e 18 horas de jejum de ração) estudados.

Denadai et al. (2002), ao avaliarem o efeito da duração do período de jejum pré-abate (zero, quatro e oito horas de jejum completo) sobre o rendimento de carcaça de frangos de corte, encontraram diferenças significativas para a variável perda de peso vivo; sendo que, ao prolongar o tempo de jejum, aumentou a perda de peso vivo. Os tratamentos de quatro e oito8 horas de jejum apresentaram maiores rendimentos de carcaças do que o tratamento de zero hora de jejum. Não foram observadas diferenças estatísticas para o rendimento dos cortes comerciais (coxa, peito, asa e dorso).

Os objetivos deste trabalho foram avaliar os efeitos de diferentes períodos de jejuns pré-abate sobre a perda de peso das aves, sobre a taxa de absorção de água das carcaças durante o préresfriamento e sobre o rendimento da carcaça inteira, dos cortes comerciais e de algumas vísceras de frangos de corte machos e fêmeas.

\section{MATERIAL E MÉTODOS}

O experimento foi realizado em granja e abatedouro comerciais, utilizando-se 240 frangos de corte da linhagem Cobb, distribuídos em cinco tratamentos com 48 frangos cada, sendo 24 fêmeas e 24 machos. As aves foram criadas até 44 dias de idade, em galpão convencional, quando foram agrupadas segundo os tratamentos. Foram utilizados quatro tratamentos com 
períodos de jejum alimentar pré-abate de quatro, oito, 12 e 16 horas, e um tratamento com 14 horas de jejum completo (ração e água).

As aves, identificadas com lacres numerados, foram pesadas antes e após o período de jejum. Ao término dos períodos de jejum, os frangos foram apanhados pelo dorso, pesados e acondicionados em caixas de transporte, na quantidade de nove frangos por caixa.

Após o abate, durante a evisceração manual, foram colhidos o fígado, a moela e o intestino, que foram posteriormente pesados. As carcaças foram pesadas antes de entrarem no préresfriamento e após o gotejamento. Esse procedimento foi realizado com o fim de se verificar a influência do tempo de jejum na taxa de absorção de água pelas carcaças.

Para a avaliação dos rendimentos de carcaça, expressos em porcentagem, foram considerados os pesos vivos das aves após o jejum e o peso da carcaça após o gotejamento. Os rendimentos dos cortes coxa e sobrecoxa, peito, dorso, asa, pés e cabeça e pescoço foram calculados em relação aos pesos das aves após o jejum, bem como, os rendimentos da moela e fígado e o peso do intestino.

O delineamento experimental foi inteiramente ao acaso, em esquema fatorial 5 x 2 (cinco tratamentos e dois sexos), com 24 repetições de uma ave cada. As diferenças entre as médias foram comparadas pelo teste SNK, sendo o grau de confiança de 95\%, segundo Sampaio (2002).

\section{RESULTADOS E DISCUSSÃO}

As interações entre sexo e período de jejum não foram significativas $(\mathrm{P}>0,05)$. $\mathrm{E}$ os resultados do peso médio das aves, antes e depois do jejum, e a perda de peso de acordo com os tratamentos e sexo, são mostrados na Tab. 1.

Tabela 1. Peso médio antes e após o jejum e perda de peso dos frangos de acordo com os tratamentos e sexo

\begin{tabular}{lcccc}
\hline Tratamento & $\begin{array}{c}\text { Peso antes do jejum } \\
(\mathrm{g})\end{array}$ & $\begin{array}{c}\text { Peso após o jejum } \\
(\mathrm{g})\end{array}$ & $\begin{array}{c}\text { Perda de peso } \\
(\mathrm{g})\end{array}$ & $\begin{array}{c}\text { Perda de peso } \\
(\%)\end{array}$ \\
\hline 4h de jejum & $2471,25 \mathrm{a}$ & $2446,15 \mathrm{a}$ & $25,10 \mathrm{e}$ & $1,0 \mathrm{e}$ \\
8h de jejum & $2485,42 \mathrm{a}$ & $2428,85 \mathrm{a}$ & $56,56 \mathrm{~d}$ & $2,3 \mathrm{~d}$ \\
12h de jejum & $2474,69 \mathrm{a}$ & $2394,79 \mathrm{~b}$ & $79,90 \mathrm{c}$ & $3,3 \mathrm{c}$ \\
16h de jejum & $2461,98 \mathrm{a}$ & $2360,00 \mathrm{c}$ & $101,98 \mathrm{~b}$ & $4,1 \mathrm{~b}$ \\
14h de jejum total & $2473,96 \mathrm{a}$ & $2353,75 \mathrm{c}$ & $120,21 \mathrm{a}$ & $4,9^{\mathrm{a}}$ \\
Machos & $2724,29 \mathrm{a}$ & $2641,96 \mathrm{a}$ & $82,33 \mathrm{a}$ & $3,0 \mathrm{a}$ \\
Fêmeas & $2222,63 \mathrm{~b}$ & $2151,46 \mathrm{~b}$ & $71,17 \mathrm{~b}$ & $3,2 \mathrm{a}$ \\
CV & 3,2 & 3,4 & 26,3 & 25,9 \\
\hline
\end{tabular}

Médias seguidas de letras distintas, na coluna, diferem entre si - teste SNK $(\mathrm{P} \leq 0,05)$.

Não houve diferença entre tratamentos quanto ao peso das aves antes do jejum ( $\mathrm{P}>0,05)$. Isso era esperado, pois foi tomado o cuidado de separar aves que representassem a média de peso do lote existente no galpão. Após o período de jejum, as aves que ficaram menos tempo (quatro e oito horas) sob restrição alimentar apresentaram maior peso vivo, seguidas pelas aves que ficaram 12 horas de jejum. As submetidas às 14 horas de jejum de água e ração apresentaram o menor peso e foram estatisticamente semelhantes àquelas que permaneceram 16 horas de jejum de ração.
A maior perda de peso vivo ocorreu no tratamento de 14 horas de jejum completo. Os demais tratamentos seguiram a relação diretamente proporcional ao tempo de jejum, semelhante ao observado por Benibo e Farr (1985), Rasmussen e Mast (1989), Lyon et al. (1991) e Denadai et al. (2002).

Os machos foram mais pesados dos que as fêmeas (Tab. 1), antes e após o jejum e apresentaram maior perda de peso, em gramas, do que as fêmeas $(\mathrm{P} \leq 0,05)$. Entretanto, a perda 
de peso, em porcentagem, não foi diferente entre machos e fêmeas $(\mathrm{P}>0,05)$. Estes resultados assemelham-se aos encontrados por Benibo e Farr (1985), que ao estudar a influência dos períodos de jejum de 10,15 e 20 horas verificaram que os machos apresentaram maior perda de peso do que as fêmeas.

Os resultados do peso médio e a porcentagem de absorção de água pela carcaça de acordo com o período de jejum e sexo são mostrados na Tab. 2.

Tabela 2. Peso médio e porcentagem de absorção de água pela carcaça de acordo com os tratamentos e sexo

\begin{tabular}{lcccc}
\hline Tratamento & $\begin{array}{c}\text { Peso antes do } \\
\text { chiller }(\mathrm{g})\end{array}$ & $\begin{array}{c}\text { Peso após } \\
\text { gotejamento }(\mathrm{g})\end{array}$ & $\begin{array}{c}\text { Absorção de água } \\
(\mathrm{g})\end{array}$ & $\begin{array}{c}\text { Absorção de água } \\
(\%)\end{array}$ \\
\hline 4h de jejum & $1895,33 \mathrm{a}$ & $2081,29 \mathrm{a}$ & $185,96 \mathrm{a}$ & $7,9 \mathrm{a}$ \\
8h de jejum & $1907,00 \mathrm{a}$ & $2084,81 \mathrm{a}$ & $177,81 \mathrm{a}$ & $7,3 \mathrm{a}$ \\
12h de jejum & $1898,00 \mathrm{a}$ & $2074,35 \mathrm{a}$ & $176,35 \mathrm{a}$ & $7,3 \mathrm{a}$ \\
16h de jejum & $1867,88 \mathrm{a}$ & $2053,88 \mathrm{a}$ & $186,00 \mathrm{a}$ & $8,1 \mathrm{a}$ \\
14h de jejum total & $1882,83 \mathrm{a}$ & $2051,67 \mathrm{a}$ & $168,83 \mathrm{a}$ & $7,0 \mathrm{a}$ \\
Fêmea & $2096,27 \mathrm{a}$ & $2286,70 \mathrm{a}$ & $190,43 \mathrm{a}$ & $7,0 \mathrm{~b}$ \\
Macho & $1684,15 \mathrm{~b}$ & $1851,70 \mathrm{~b}$ & $167,55 \mathrm{~b}$ & $7,9 \mathrm{a}$ \\
CV & 3,9 & 4,4 & 25,6 & 26,6 \\
\hline
\end{tabular}

Médias seguidas de letras distintas, na coluna, diferem entre si - teste $\mathrm{SNK}(\mathrm{P} \leq 0,05)$.

Mesmo originadas de frangos com diferenças no peso vivo pós-jejum, o peso da carcaça antes de passar pelo chiller não foi influenciado pelo período de jejum $(\mathrm{P}>0,05)$. Também não houve diferença entre tratamentos no peso da carcaça após o gotejamento, ou seja, o tempo de jejum não influenciou na taxa de absorção de água pela carcaça. Os resultados assemelham-se aos encontrados por Benibo e Farr (1985) que também não observaram efeito do período de jejum na absorção de água da carcaça. Rasmussen e Mast (1989) não encontraram diferença significativa para peso da carcaça eviscerada antes do chiller nos diferentes tratamentos, mas a taxa de absorção de água aumentou, gradualmente, com o aumento do tempo de jejum $(\mathrm{P} \leq 0,05)$.

A absorção de água de acordo com o sexo (Tab. 2) mostrou que o peso da carcaça dos machos, antes de passarem pelo chiller e após o gotejamento, foram maiores que os das fêmeas $(\mathrm{P} \leq 0,05)$. Em termos absolutos, a absorção de água pela carcaça dos machos foi maior que as das fêmeas, mas em termos percentuais a absorção de água pela carcaça das fêmeas, foi maior que a dos machos $(\mathrm{P} \leq 0,05)$. Benibo e Farr (1985) encontraram que as fêmeas, em valores absolutos, absorvem mais água que os machos, mas esses autores não observaram diferença entre sexo para a taxa de absorção de água pela carcaça.

O rendimento de carcaça em relação ao peso das aves após o período de jejum (Tab. 3) apresentou diferença significativa $(\mathrm{P} \leq 0,05)$. As aves dos tratamentos de 12 e 16 horas de jejum de ração e 14 horas de jejum completo apresentaram o maior rendimento de carcaça e não foram diferentes dos frangos do tratamento de oito horas de jejum. Os frangos submetidos a quatro horas de jejum apresentaram o menor rendimento de carcaça. Esses resultados assemelham-se aos encontrados por Lyon et al. (1991), Baião et al. (1992) e Denadai et al. (2002) que demonstraram que as aves que não sofreram jejum apresentaram o menor rendimento de carcaça. Entretanto Rasmussen e Mast (1989) não encontraram diferenças para o rendimento de carcaça nos períodos de zero, seis, 12, e 18 horas de jejum de ração $(\mathrm{P}>0,05)$. 
Tabela 3. Rendimentos de carcaças de acordo com os tratamentos e sexo, utilizando o peso das aves após o jejum

\begin{tabular}{lcc}
\hline Tratamento & $\begin{array}{c}\text { Carcaça eviscerada sem pés, } \\
\text { cabeça e pescoço }(\mathrm{g})\end{array}$ & $\begin{array}{c}\text { Rendimento em relação ao peso } \\
\text { após jejum (\%) }\end{array}$ \\
\hline 4h de jejum & $1818,40 \mathrm{a}$ & $74,4 \mathrm{~b}$ \\
8h de jejum & $1825,52 \mathrm{a}$ & $75,2 \mathrm{ab}$ \\
12h de jejum & $1817,23 \mathrm{a}$ & $75,9 \mathrm{a}$ \\
16h de jejum & $1792,19 \mathrm{a}$ & $76,0 \mathrm{a}$ \\
14h de jejum total & $1788,13 \mathrm{a}$ & $76,0 \mathrm{a}$ \\
Macho & $1986,46 \mathrm{a}$ & $75,2 \mathrm{~b}$ \\
Fêmea & $1630,13 \mathrm{~b}$ & $75,8 \mathrm{a}$ \\
CV & 4,8 & 2,9 \\
\hline
\end{tabular}

Médias seguidas de letras distintas, na coluna, diferem entre si - teste SNK $(\mathrm{P} \leq 0,05)$

Apesar de os machos apresentarem carcaças mais pesadas (Tab. 3), as fêmeas apresentaram rendimento de carcaça superior ao dos machos $(\mathrm{P} \leq 0,05)$.

Para os rendimentos dos cortes comerciais utilizando o peso das aves após o jejum (Tab. 4) foi observado que os rendimentos de coxa e sobrecoxa e asa não foram afetados pelos períodos de jejum $(\mathrm{P}>0,05)$. Para o rendimento de peito, os frangos do tratamento de 14 horas de jejum completo apresentaram o maior rendimento de peito, mas não foram diferentes dos tratamentos de oito, 12 e 16 horas $(\mathrm{P} \leq 0,05)$. $\mathrm{O}$ tratamento de quatro horas apresentou o menor rendimento de peito $(\mathrm{P} \leq 0,05)$. $\mathrm{O}$ rendimento de dorso foi maior para as aves do tratamento de 14 horas de jejum completo $(\mathrm{P}>0,05)$. Os tratamentos de 16 horas de jejum e de 14 horas de jejum completo apresentaram os maiores rendimentos para pés, cabeça e pescoço e seus resultados foram diferentes dos demais tratamentos $(\mathrm{P} \leq 0,05)$.

Tabela 4. Rendimentos de cortes de acordo com os diferentes períodos de jejum e sexo, utilizando os pesos das aves após o jejum

\begin{tabular}{lccccc}
\hline Tratamento & $\begin{array}{c}\text { Coxa + sobrecoxa } \\
(\%)\end{array}$ & $\begin{array}{c}\text { Peito } \\
(\%)\end{array}$ & $\begin{array}{c}\text { Dorso } \\
(\%)\end{array}$ & $\begin{array}{c}\text { Asa } \\
(\%)\end{array}$ & $\begin{array}{c}\text { Pés, cabeça e pescoço } \\
(\%)\end{array}$ \\
\hline 4h de jejum & $25,6 \mathrm{a}$ & $27,3 \mathrm{~b}$ & $8,3 \mathrm{~b}$ & $9,5 \mathrm{a}$ & $10,7 \mathrm{~b}$ \\
8h de jejum & $26,0 \mathrm{a}$ & $27,6 \mathrm{ab}$ & $8,0 \mathrm{~b}$ & $9,5 \mathrm{a}$ & $10,6 \mathrm{~b}$ \\
12h de jejum & $25,7 \mathrm{a}$ & $27,8 \mathrm{ab}$ & $8,3 \mathrm{~b}$ & $9,7 \mathrm{a}$ & $10,7 \mathrm{~b}$ \\
16h de jejum & $25,4 \mathrm{a}$ & $28,0 \mathrm{ab}$ & $8,2 \mathrm{~b}$ & $9,5 \mathrm{a}$ & $11,0 \mathrm{a}$ \\
14h de jejum total & $26,0 \mathrm{a}$ & $28,3 \mathrm{a}$ & $8,8 \mathrm{a}$ & $9,8 \mathrm{a}$ & $11,1 \mathrm{a}$ \\
Macho & $26,1 \mathrm{a}$ & $27,4 \mathrm{~b}$ & $8,4 \mathrm{a}$ & $9,5 \mathrm{~b}$ & $11,4 \mathrm{a}$ \\
Fêmea & $25,3 \mathrm{~b}$ & $28,1 \mathrm{a}$ & $8,2 \mathrm{a}$ & $9,7 \mathrm{a}$ & $10,3 \mathrm{~b}$ \\
CV & 5,2 & 5,4 & 11,2 & 6,4 & 6,3 \\
\hline
\end{tabular}

Médias seguidas de letras distintas, na coluna, diferem entre si - teste SNK (P $\leq 0,05)$.

Considerando o sexo das aves (Tab. 4) e os rendimentos dos cortes, foi observado que os machos apresentaram rendimento de coxa e sobrecoxa e pés, cabeça e pescoço maior que os das fêmeas $(\mathrm{P}<0,05)$. As fêmeas obtiveram maior rendimento de peito e asa $(\mathrm{P} \leq 0,05)$, e não houve diferença entre os sexos para o rendimento do dorso $(\mathrm{P}>0,05)$.
A Tab. 5 apresenta o conteúdo de ração na moela de acordo com os tratamentos e sexo. O conteúdo de ração existente na moela sofreu influência dos períodos de jejum, sendo que a maior quantidade de ração foi observada nas moelas das aves que foram submetidas ao menor período de jejum (quatro horas), o que era esperado, pois estes frangos tiveram menor 
tempo de esvaziamento do trato gastrintestinal. O período de oito horas de jejum apresentou conteúdo de moela menor que o tratamento de quatro horas, mas semelhante aos tratamentos de 12 horas e 14 horas de jejum completo, sendo que o tratamento que apresentou o menor conteúdo da moela foi o de 16 horas de jejum. Para o peso da moela vazia não foram encontradas diferenças entre os tratamentos $(\mathrm{P}>0,05)$.

Os machos apresentaram um maior peso de moela $(\mathrm{P} \leq 0,05)$ em relação às fêmeas $($ Tab. 5$)$, porém não foi observada diferença $(\mathrm{P}>0,05)$ para o conteúdo de ração na moela em relação ao sexo.

Tabela 5. Peso e conteúdo de ração na moela de acordo com os tratamentos e sexo

\begin{tabular}{lccc}
\hline Tratamento & Moela vazia $(\mathrm{g})$ & $\begin{array}{c}\text { Conteúdo de ração na } \\
\text { moela }(\mathrm{g})\end{array}$ & $\begin{array}{c}\text { Conteúdo de ração na } \\
\text { moela }(\%)\end{array}$ \\
\hline 4h de jejum & $42,29 \mathrm{a}$ & $14,46 \mathrm{a}$ & $25,0 \mathrm{a}$ \\
8h de jejum & $40,21 \mathrm{a}$ & $10,96 \mathrm{~b}$ & $21,3 \mathrm{~b}$ \\
12h de jejum & $40,29 \mathrm{a}$ & $8,88 \mathrm{bc}$ & $17,9 \mathrm{~b} \mathrm{c}$ \\
16h de jejum & $41,92 \mathrm{a}$ & $8,50 \mathrm{c}$ & $16,9 \mathrm{c}$ \\
14h de jejum total & $40,56 \mathrm{a}$ & $10,08 \mathrm{bc}$ & $19,6 \mathrm{~b} \mathrm{c}$ \\
Macho & $43,31 \mathrm{a}$ & $10,81 \mathrm{a}$ & $19,5 \mathrm{a}$ \\
Fêmea & $38,80 \mathrm{~b}$ & $10,34 \mathrm{a}$ & $20,7 \mathrm{a}$ \\
CV & 14,6 & 42,8 & 35,2 \\
\hline Médias seguidas de letras distintas,
\end{tabular}

Médias seguidas de letras distintas, na coluna, diferem entre si - teste $\operatorname{SNK}(\mathrm{P} \leq 0,05)$.

Tabela 6. Peso e rendimento do intestino e fígado de acordo com os tratamentos e sexo

\begin{tabular}{lcccc}
\hline Tratamento & $\begin{array}{c}\text { Peso do intestino } \\
(\mathrm{g})\end{array}$ & $\begin{array}{c}\text { Peso dó intestino } \\
(\%)\end{array}$ & $\begin{array}{c}\text { Peso do fígado } \\
(\mathrm{g})\end{array}$ & $\begin{array}{c}\text { Rendimento do } \\
\text { fígado }(\%)\end{array}$ \\
\hline 4h de jejum & $116,58 \mathrm{a}$ & $4,8 \mathrm{a}$ & $54,75 \mathrm{a}$ & $2,2 \mathrm{a}$ \\
8h de jejum & $108,38 \mathrm{~b}$ & $4,5 \mathrm{~b}$ & $51,04 \mathrm{~b}$ & $2,1 \mathrm{~b}$ \\
12h de jejum & $96,42 \mathrm{c}$ & $4,0 \mathrm{c}$ & $50,38 \mathrm{bc}$ & $2,1 \mathrm{~b}$ \\
16h de jejum & $95,88 \mathrm{c}$ & $4,1 \mathrm{c}$ & $48,00 \mathrm{bc}$ & $2,0 \mathrm{~b}$ \\
14h de jejum total & $99,92 \mathrm{c}$ & $4,3 \mathrm{bc}$ & $47,17 \mathrm{c}$ & $2,0 \mathrm{~b}$ \\
Macho & $108,22 \mathrm{a}$ & $4,1 \mathrm{~b}$ & $52,82 \mathrm{a}$ & $2,0 \mathrm{~b}$ \\
Fêmea & $98,65 \mathrm{~b}$ & $4,6 \mathrm{a}$ & $47,72 \mathrm{~b}$ & $2,2 \mathrm{a}$ \\
CV & 14,7 & 14,9 & 13,5 & 13,6 \\
\hline
\end{tabular}

Médias seguidas de letras distintas, na coluna, diferem entre si - $\mathrm{SNK}(\mathrm{P} \leq 0,05)$.

Os dados de peso do intestino se encontram na Tab. 6. O peso do intestino foi maior $(\mathrm{P} \leq 0,05)$ para as aves submetidas a quatro horas de jejum, seguido pelas aves submetidas a oito horas. Os demais tratamentos apresentaram menores peso de intestino e foram semelhantes entre si, demonstrando que quanto maior for o tempo de jejum, maior será o esvaziamento do trato gastrintestinal, o que é desejável nas operações de abate. Os dados de porcentagem do intestino em relação ao peso das aves seguiram a mesma tendência observada em seu peso absoluto, ou seja, a maior porcentagem de intestino foi apresentada pelo tratamento de quatro horas de jejum pré-abate $(\mathrm{P} \leq 0,05)$. Os resultados demonstram que o peso do intestino foi influenciado pelo sexo dos frangos, sendo que os machos apresentaram os intestinos mais pesados do que as fêmeas. No entanto, o peso do intestino em relação ao peso das aves após jejum foi maior para as fêmeas $(\mathrm{P} \leq 0,05)$.

Os dados de peso e rendimento do fígado, apresentados na Tab. 6, demonstram que o pesos dos fígados das aves do tratamento com quatro horas de jejum pré-abate foram maiores $(\mathrm{P} \leq 0,05)$ que os demais tratamentos. Os tratamentos de oito, 12 e 16 horas de jejum não apresentaram 
diferenças entre si, porém os frangos do tratamento de 14 horas apresentaram o menor peso de fígado em relação aos frangos do tratamento de quatro e oito horas de jejum. Em relação ao peso das aves após o jejum pré-abate, o tratamento de quatro horas de jejum apresentou rendimento de fígado maior que os outros tratamentos, que foram semelhantes entre si $(\mathrm{P} \leq 0,05)$. Northcutt et al. (1997) ao verificarem a relação do período jejum pré-abate (zero, três, nove, $12,14,16$ e 18 horas) com as condições das vísceras não encontraram efeitos significativos para os rendimentos de fígado. Apesar de os machos apresentarem o fígado mais pesado, as fêmeas apresentam os maiores rendimentos dessa víscera $(\mathrm{P} \leq 0,05)$.

\section{CONCLUSÕES}

De acordo com os resultados apresentados neste experimento, conclui-se que a perda de peso vivo dos frangos antes do abate é diretamente proporcional ao período de jejum e o período de jejum não influencia na taxa de absorção de água pelas carcaças, porém as carcaças das fêmeas absorvem mais água que as dos machos. Os períodos de jejum pré-abate de 12, 14 e 16 horas proporcionam melhores rendimentos de carcaça e, o período de quatro horas proporciona pior rendimento. As fêmeas apresentam rendimento de carcaça superior aos dos machos e os rendimentos dos cortes comerciais não demonstraram resultados conclusivos em relação aos períodos de jejum. As aves que permanecem menor tempo em jejum apresentam maiores peso de intestino e de fígado.

\section{REFERÊNCIAS BIBLIOGRÁFICAS}

BAIÃO, N.C.; FERREIRA, M.O.O; TEIXEIRA, A.A. et al.. Efeitos do tipo e período de jejum sobre a perda do peso vivo e rendimento de carcaça de frangos de corte. Arq. Bras. Med. Vet. Zootec., v. 44, p.205-213, 1992.

BENIBO, B.S.; FARR, A.J. The effects of feed and water withdrawal and holding shed treatments on broiler yield parameters. Poult. Sci., v. 64, p.920- 924, 1985.

DENADAI, J.C.; MENDES, A.A.; GARCIA, R.G. et al. Efeito da duração do período de jejum pré-abate sobre rendimento de carcaça e a qualidade da carne do peito de frangos de corte. Rev. Bras. Ciên. Avic., v.4, p.101- 109, 2002.

LYON, C.E.; PAPA, C.M.; WILSON Jr, R.L. Effect of feed withdrawal on yields, muscle $\mathrm{pH}$, and texture of broiler breast meat. Poult. Sci., v.70, p.1020- 1025, 1991.

NORTHCUTT, J.K.; SAVAGE, S.I.; VEST, L.R. Relationship between feed withdrawal and viscera condition of broilers. Poult. Sci., v.76, p.410- 414, 1997.

PORTARIA n. 210 de 10 de novembro de 1998. Aprovar o Regulamento Técnico de Inspeção Tecnológica e Higiênico-sanitária de carnes de aves, 1998. 26p.

RASMUSSEN, A.L.; MAST, M.G. Effect of feed withdrawal on composition and quality of broiler meat. Poult. Sci., v.68, p.1109- 1113, 1989.

SAMPAIO, I.B.M. Estatística aplicada à experimentação animal. 2.ed. Belo Horizonte: FEPMVZ - Editora, 2002. 265p. 